Bangladesh J. Bot. 48(4): 967-972, 2019 (December)

\title{
STABILITY ANALYSIS FOR QUALITY ATTRIBUTES IN DURUM WHEAT (TRITICUM DURUM L.) GENOTYPES
}

\author{
Himani Punia, Shashi Madan, Anurag Malik ${ }^{1 *}$ and SK Sethi ${ }^{2}$ \\ Department of Biochemistry, College of Basic Sciences \& Humanities, \\ CCS Haryana Agricultural University, Hisar-125004, Haryana, India
}

Keywords: Durum wheat, Stability analysis, Quality attributes

\begin{abstract}
Wheat contributes more than $50 \%$ of calories to the people worldwide. In terms of appearance, colour, texture and flavor, the quality is determined by raw material, processing methods and other ingredients. The glutenin and gliadin proteins influence dough properties. Thirty-six durum wheat genotypes were evaluated for various quality traits viz. grain appearance score, grain hardness, sedimentation value and wet and dry gluten content. The superior genotypes for the physical characteristics of grains were PDW 337, UAS 448 and PDW 335. Wet and dry gluten were maximum in UAS 448 and WHD 954. PDW 337 (44 ml) and DDW $27(44 \mathrm{ml})$ had highest sedimentation value. Present study reveals the identification of superior durum wheat genotypes which may be used in future breeding programmes to enhance the quality for human nutrition and specific end-uses.
\end{abstract}

\section{Introduction}

Wheat is a major crop in temperate countries. It is being used as livestock feed and human's food. The success of wheat largely depends on its high yield potential and adaptability and also on the gluten content, which imparts the visco-elastic properties that allows its dough to be processed into pasta, noodles, bread and other food products. Durum wheat (Triticum durum L.) offers a unique advantage over bread wheat due to wide adaptability over seasonal variations and presence of a strong visco-elastic storage protein complex called gluten. It has unique characteristics which have made it the most suitable raw material for the production of pasta products such as spaghetti, macaroni and vermicelli etc. The high protein content, excellent golden amber color, kernel hardness, kernel size, granular semolina and superior cooking quality of durum wheat makes it the most suitable wheat for manufacturing high quality pasta products and diverse range of foods (Motalebi et al. 2007, Soomro et al. 2014). It contains high amount of protein, gluten and said to be the hardiest of all wheat kernels. The pasta quality of durum wheat is influenced mainly by the physical and biochemical properties of wheat kernels which are in turn determined by genotype, environment and their interactions (Taghouti et al. 2010). For making good quality pasta products durum wheat with protein greater than 13 per cent, sedimentation value above 40 millilitre $(\mathrm{ml})$ and viscosity greater than 90 per cent are needed.

Quality is an important aspect of durum wheat and it demands specific quality traits as well as functionality. Grain texture, protein content, gluten and starch composition in the endosperm are the major determinants of end product quality. The quality of wheat is largely dependent upon its chemical composition which is influenced by genetic, environmental factors and processing conditions. Gluten which constitutes around the 80 per cent of the endosperm protein is composed of gliadins and glutenins. Gliadins (monomeric) and glutenins (polymeric) are the most important

*Author for correspondence: < anuragmailk00@gmail.com >. ${ }^{1}$ Department of Seed Science and Technology, College of Agriculture, CCS Haryana Agricultural University, Hisar-125004, Haryana, India. ${ }^{2}$ Department of Genetics and Plant breeding, College of Agriculture, COA, CCS Haryana Agricultural University, Hisar125004, Haryana, India. 
genetic components, responsible for visco-elasticity in dough which determines the end product quality. Understanding the molecular basis for visco-elasticity of wheat gluten-protein is an important pre-requisite for manipulating their properties in order to improve the quality for traditional uses and to develop new properties for novel uses. Recent research has shown that the presence of $\gamma$-gliadin 45 is a reliable marker of good pasta quality (Tofiq et al. 2012). The marker is now used for screening early generation material in many durum wheat breeding programmes (Sethi et al. 1995, Madan et al. 2006, Sethi and Verma 2012). The present investigation evaluates the durum wheat genotypes for various quality attributes under irrigated conditions to identify the superior genotypes to improve the breeding quality of existed genotypes.

\section{Materials and Methods}

The experiment was carried out during rabi season at Wheat and Barley Section, Department of Genetics \& Plant Breeding, CCS Haryana Agricultural University, Hisar (Haryana). Thirty-six durum wheat genotypes were grown under conventional cropping system in a farm scale experiment in a complete randomized block design (RBD) with three replications. The genotypes were sown with a plot size of $6 \times 1.20$ sq. meter. Quality analysis was carried out on whole meal and whole grains obtained after harvesting. The grains were milled to whole meal with a Cyclotec mill-PBI (Italy) and sieved with a $1 \mathrm{~mm}$ mesh. In grain appearance score, grain size, shape, soundness, colour and lustre were collectively taken into consideration to judge the grain appearance to 10-point score. Grain hardness was measured by pressing ten average sized well fitted grains in the grain hardness tester (Manufactured by Kiya Seisakusho Ltd., Japan). Sedimentation value was determined by the method described by Axford et al. (1979).

The experimental data were analyzed by the application of RBD design using OPSTAT software available on CCSHAU home page (Sheoran O.P.).

\section{Results and Discussion}

Physico-chemical characteristics of wheat is one of the important parameters which decides the quality of wheat in the field itself. It includes color, size, shape and weight of the grains. The physical characteristics which influence the grain quality like grain appearance score, and grain hardness varied significantly among different wheat genotypes (Figs 1 and 2). Grain appearance score merits consideration in grain trade. Grain size, shape, soundness, colour and lusture are collectively taken into consideration to judge the grain appearance out of total score of 10.0. It ranged from 4.5 to 6.2 with an overall mean value of 5.4. Highest grain appearance score was observed in PDW 337 (6.2) followed by UAS 448 (6.1) and lowest was observed in UPD 95 (4.5). These results were at par to the results of Gaines et al. (1996) and Mangova et al. (2013). Grain hardness is a strong predictor of dough handling and loaf texture characteristics (Hruskova and Svec 2009). Grain hardness of durum wheat genotypes ranged from 6.20 to $14.07 \mathrm{~kg} / \mathrm{seed}$ with an overall mean value of $10.44 \mathrm{~kg} / \mathrm{seed}$ (Fig. 2). The genotypes showing maximum value of grain hardness were PDW 337 (14.07 kg/seed) followed by PDW $335(13.2 \mathrm{~kg} / \mathrm{seed})$ while minimum value was observed in HD 2967 (6.20 kg/seed).

Apart from good physical characteristics of the grains, nutritional quality i.e., nutrient composition and availability of nutrients to the body are also very important. Sedimentation value, an indicator of gluten strength depends on wheat protein composition and wet gluten content (Yanchev and Ivanov 2012). Sedimentation value of durum wheat genotypes ranged from 26 to 44 $\mathrm{ml}$ with an overall mean value of $35 \mathrm{ml}$ (Fig. 3.). The genotypes which performed better were PDW $337(44 \mathrm{ml})$ and DDW $27(44 \mathrm{ml})$ followed by UAS $448(43 \mathrm{ml})$ while the lowest value was reported in PDW 337 (26 ml). Nachit et al. (1998) performed multilocation trails which showed 
significant genotype-environment (GE) interactions for grain quality parameters. High values of sedimentation test (SDS) were associated with the presence of $\gamma-45$ gliadin, while low values with the presence of $\gamma-42$ gliadin. The results showed that in both environments, protein content and vitreousness were more influenced by environments than by genotypes or GE interactions, whereas carotene content, kernel weight, test weight, SDS and SDS index were influenced by genotypes than by environments or GE interactions.

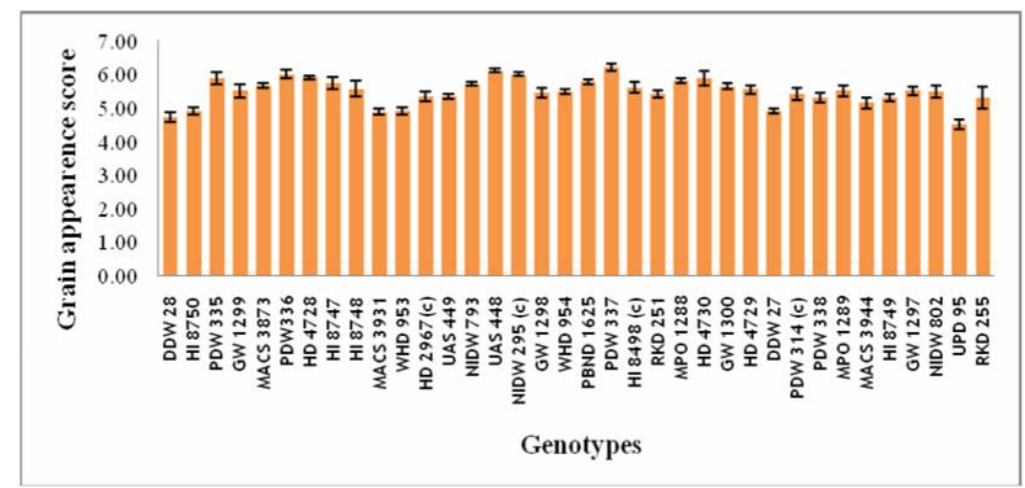

Fig. 1. Grain appearance score (Max. score 10.0) in durum wheat genotypes. C.D. at 5 per cent $=0.403$.

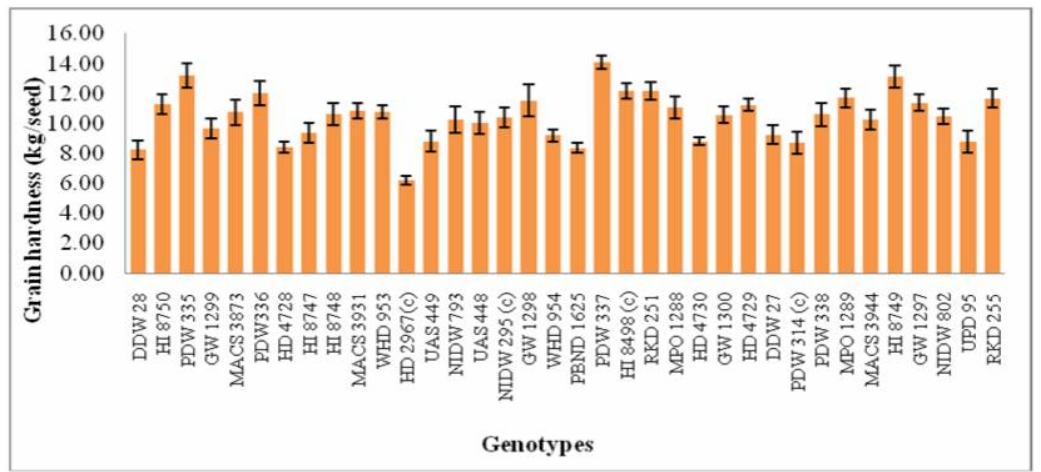

Fig. 2. Grain hardness (kg/seed) in durum wheat genotypes. C.D. at 5 per cent $=1.801$.

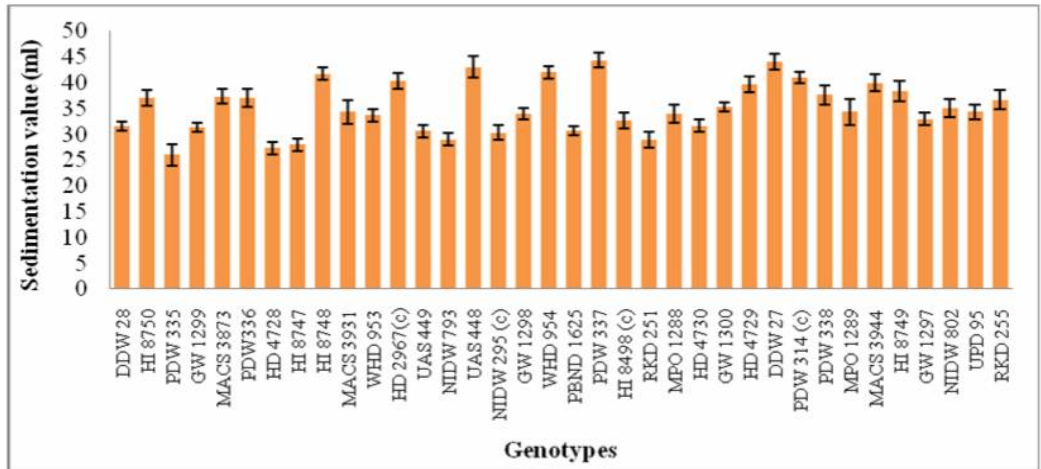

Fig. 3. Sedimentation value $(\mathrm{ml})$ in durum wheat genotypes. C.D. at 5 per cent $=4.315$. 
Gluten is a visco-elastic proteinaceous substance obtained after washing out the starch granules from wheat dough. The quality of resulting gluten is a notable index of wheat baking potential. Knowing the importance of wet and dry gluten, it was evaluated. Wet gluten content of durum wheat genotypes is depicted in Fig. 4. It ranged from 21.90 to $34.57 \%$ with an overall mean value of 26.54 per cent. UAS 448 contained highest wet gluten i.e. $34.57 \%$ followed by $33.33 \%$ in WHD 954 and $21.90 \%$ in PDW 336. Dry gluten content of durum wheat genotypes ranged from 8.50 to $9.67 \%$ with an overall mean value of $8.96 \%$ (Fig. 5). Dry gluten with maximum value was observed in UAS $448(9.67 \%)$ followed by WHD $954(9.53 \%)$ and minimum was observed in DDW $27(8.50 \%)$. Dry gluten content was correlated positively with the wet gluten content (Zaidel et al. 2009, Baslar and Ertugay 2011). Similar findings have also been reported earlier by Banu et al. (2009), Sakin et al. (2011) and Desheva et al. (2014). Berot et al. (1996) studied the technological properties of the wheat gluten protein fractions. Gliadin rich fractions increased the extensibility of the dough and reduced its resistance to deformation. Glutenin rich fractions had opposite effect and increased dough resistance more than that of equally concentrated whole gluten. Yves et al. (1998) observed that wheat storage proteins are responsible for the visco-elastic properties of dough. Their effect on dough rheology depends on the glutenin components and the proportion of gliadins, high and low molecular weight glutenin subunits.

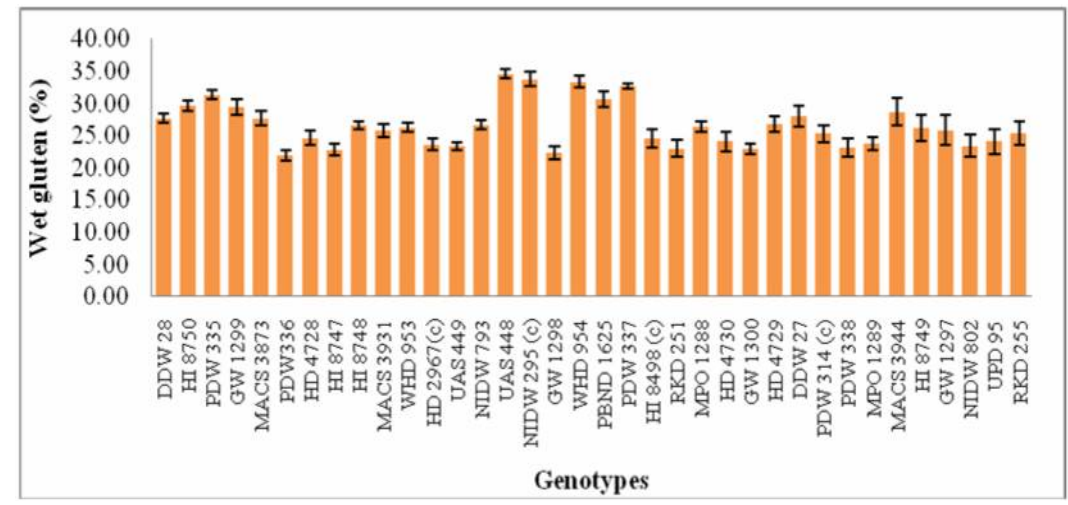

Fig. 4. Wet gluten content (per cent dry weight basis) in durum wheat genotypes. C.D. at $5 \%=3.548$.

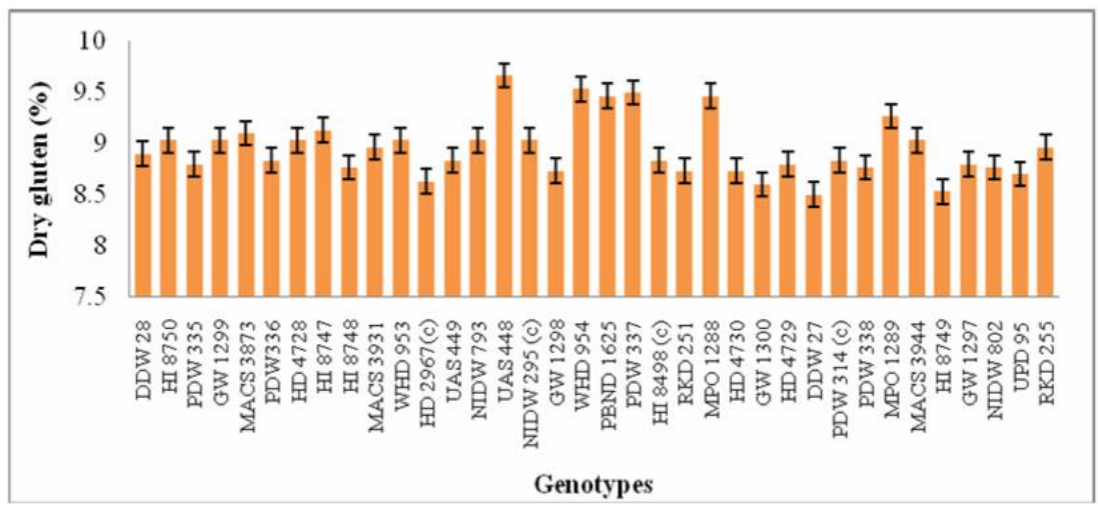

Fig. 5. Dry gluten content (per cent dry weight basis) in durum wheat genotypes. C.D. at $5 \%=0.484$. 
The variation in gluten content among different wheat genotypes may be ascribed to the variation in genetic makeup of wheat varieties, climatic conditions and growth locations (Randhawa et al. 2002, Safdar et al. 2009). Rao et al. (1976) studied the physico-chemical characteristics of 24 Indian and three Canadian $T$. durum wheat varieties. The range values for crude protein (\%), wet gluten (\%) a pigments (ppm) were 10.60 to $13.27 \%, 28.20$ to $34.3 \%$ and 2.72 to $4.56 \mathrm{ppm}$, respectively for Indian wheat, whereas for Canadian wheat the values were 13.26 to $16.80 \%, 40.60$ to $52.60 \%$ and 4.87 to $6.47 \mathrm{ppm}$, respectively. Anjum and Walker (2000) studied eight wheat varieties for protein, dry and wet gluten content and they observed that protein content in grains ranged from 11.99 to $13.80 \%$, dry and wet gluten content ranged from 8.88 to $10.91 \%$ and 27.60 to $35.18 \%$, respectively. Tofiq et al. (2012) reported that storage proteins like gliadins and glutenins are most important genetic components, responsible for visco-elasticity in dough and they also concluded that the presence of $\gamma$-gliadin 45 was a reliable marker of good pasta quality. The evaluated germplasm showed gliadin $\gamma-45$ associated with good durum quality and $\gamma-42$ associated with bad durum quality. The marker is now used for screening early generation material in many durum wheat breeding programme (D'Ovidio et al. 1991, Yildirim et al. 2011). Mangova et al. (2013) studied the grain quality of 16 durum wheat varieties with different origin. Observations were taken on 1000-kernel weight, test weight, vitreousness, crude protein, wet and dry gluten, yellow pigments and sedimentation value (SDS). The results showed that crude protein ranged from 11.8-16.1\%, wet and dry gluten ranged from $24.1-33.7 \%$ and 7.8 $11.5 \%$, respectively, yellow pigment ranged from $7.1-9.9 \mathrm{ppm}$ and sedimentation value ranged from $18.3-68.0 \mathrm{~cm}^{3}$. Thus, present investigation showed that the genotypes UAS 448, PDW 337, WHD 954, HD 4730 and PBND 1625 were found promising and may be used in crossing programme in order to improve grain quality along with yield.

\section{References}

Anjum FM and Walker CE 2000. Grain, flour and bread making properties of eight Pakistani hard white spring wheat cultivars grown at three different locations for 2 years. Int. J. Food Sci. Technol. 35: $407-$ 416.

Axford DWE, Mc-Dermott EE and Redman DG 1979. Note on SDS-sedimentation test and bread making quality: Comparison with pelshenke and zeleny-tests. Cereal Chem. 56: 582-584.

Banu I, Stoenescu G, Ionescu VS, Aprodu I and Vasilean I 2009. Studies concerning the quality of bread wheat varieties from Romania. Scientific Study Res. 10(2): 171-178.

Baslar M and Ertugay MF 2011. Determination of protein and gluten quality-related parameters of wheat flour using near-infrared reflectance spectroscopy (NIRS). Turk. J. Agric. 35: 139-144.

Berot S, Chiron H, Nicolas M, Gautiens GB and Popineau Y 1996. Pilot scale preparation of wheat gluten protein fraction II technological properties of the fractions. J. Food Sci. Technol. 31(1): 77-83.

Desheva G, Valchinova E, Kyosev B and Stoyanova S 2014. Grain physical characteristics and bread-making quality of alternative cereals towards common and durum wheat. Emir. J. Food Agric. 26(5): 418-424.

D'Ovidio R, Tanzarella OA and Porceddu E 1991. Cloning and sequencing of a PCR amplified gammagliadin gene from durum wheat (Triticum turgidum (L.) Thell. conv. durum (Desf.). Plant Sci. 75: 229236.

Gaines CS, Finney PF, Fleege LM and Andrews LC 1996. Predicting a hardness measurement using the single-kernel characterization system. Cereal Chem. 73: 278-283.

Hruskova M and Svec I 2009. Wheat hardness in relation to other quality factors. Czech J. Food Sci. 27: 240248.

Madan S, Gupta RK and Sethi SK 2006. Nutritional status of durum wheat genotypes. Nat. J. Plant Improv. 8: 125-127. 
Mangova M, Menkovska M, Petrova I and Kolev T 2013. Variety - The main factor for improving the quality of durum wheat (Triticum durum Desf.). Maced. J. Animal Sci. 3(2): 213-217.

Motalebi M, Keshavarzi M and Naghavi MR 2007. Glutenin subunit composition in durum (Triticum durum) landraces and cultivars. Asian J. Plant Sci. 6: 399-402.

Nachit MM, Baum M, Impiglia A and Ketata H 1998. Studies on some quality traits in durum wheat grown in Mediterranean environment. CHIEAM-IAZO, Zaragoza, Spain. pp.181-187.

Randhawa MA, Anjum FM and Butt MS 2002. Physico-chemical and milling properties of new spring wheats grown in Punjab and Sind for the production of pizza. Int. J. Agric. Biol. 4: 482- 484.

Rao HP, Rahim A, Prabhavathi C and Shurpalekar SR 1976. Physico-chemical, rheological and milling characteristics of India durum wheats. J. Sci. Food Agric. 13(6): 317-322.

Safdar MN, Naseem K, Siddiqui N, Amjad M, Hameed T and Khalil S 2009. Quality evaluation of different wheat varieties for the production of unleavened flat bread (Chapatti). Pak. J. Nutr. 8(11): 1773-1778.

Sakin MA, Duzdemir O, Sayaslan A and Yuksel F 2011. Stability properties of certain durum wheat genotypes for major quality characteristics. Turk. J. Agric. 35: 343-355.

Sethi SK and Verma SR 2012. Durum wheat: Nutrient rich staple food in 6th International wheat seminar on wheat and wheat products: Moving towards Food and Nutrition Security. New Delhi Souvenir. pp. 155156.

Sethi SK, Srivastava RB, Yunus M and Yadav B 1995. Relative efficiency of different methods of generating variability in Triticum durum. Indian J. Genet. Plant Breed. 55(3): 273-278.

Soomro AF, Nizamani FK, Ahadkolachi A, Soomro KB and Solangi KA 2014. Evaluation of different durum wheat varieties under stress conditions (Brackish water \& coarse textured soil). Int. J. Curr. Res. Acad. Rev. 2(7): 11-17.

Taghouti M, Gaboun F, Nsarellah N, Rhrib R, El-Haila M, Kamar F, Abbad-Andaloussi and Udupa SM 2010. Genotype $\times$ environment interaction for quality traits in durum wheat cultivators adapted to different environments. Afr. J. Biotechnol. 9: 3054-3062.

Tofiq SI Muhammed AA and Ameen HTN 2012. Characterization of durum wheat genotypes by seed storage-protein electrophoresis. J. Zankoy Sulaimani. 14(1): 10-14.

Yanchev I and Ivanov U 2012. Comparative study of physical, chemical and technological properties of the Greek and Bulgarian common wheat varieties. Field Crop Sci. 8(2): 219-226.

Yildirim A, Eserkaya T, Gulec AE, Sayaslan A, Koyuncu M, Sonmezogl OA and Kandemir N 2011. Molecular and biochemical screening of Turkish durum wheat landraces for gliadin and LMW-glutenin proteins associated with pasta-cooking quality. Turk. J. Field Crops. 16: 220-224.

Yves N, Jean PM, Sandra DP and Yves P 1998. Analysis of wheat storage proteins by exhaustive sequential extraction followed by RP-HPLC nitrogen determination. J. Sci. Food Agric. 77: 96-102.

Zaidel ADN, Chin NL, Yusof YA and Rahman AR 2009. Analysis and correlation studies on gluten quantity and quality during production. J. Appl. Sci. 9(9): 1686-1694. 